\title{
Knowledge, attitudes, and practices of tertiary education students in regard to air pollution in Windhoek, Namibia: a cross sectional study
}

HAUSHIKU KEMBA ( $\sim$ khkemba@gmail.com )

University of Pretoria https://orcid.org/0000-0002-0952-405X

Nkwenika Tshifhiwa

South African Medical Research Council

Nkosi Vusumuzi

South African Medical Research Council

Research article

Keywords: Air pollution, Windhoek, Namibia, Tertiary students

Posted Date: September 21st, 2020

DOI: https://doi.org/10.21203/rs.3.rs-34388/v2

License: (c) This work is licensed under a Creative Commons Attribution 4.0 International License.

Read Full License 


\title{
Knowledge, attitudes, and practices of tertiary education students in regard to air pollution in Windhoek, Namibia: a cross sectional study.
}

\author{
Haushiku Kemba ${ }^{1 *}$, Tshifhiwa Nkwenika ${ }^{4}$, and Vusumuzi Nkosi ${ }^{1,2,3}$ \\ 1 School of Health Systems and Public Health, Faculty of Health Sciences, University of Pretoria, Pretoria 0001 \\ 2 Environment and Health Research Unit, South African Medical Research Council, Johannesburg, 2094, South \\ Africa \\ 3 Department of Environmental Health, Faculty of Health Sciences, University of Johannesburg, Johannesburg \\ 2094, South Africa. \\ 4 Biostatistics Unit, South African Medical Research Council, Pretoria, 0001 \\ * Correspondence: khkemba@ gmail.com, Cell: +264813397616
}

\begin{abstract}
:
Background: Knowing the residents' knowledge, attitude, and practices to air pollution is necessary for developing interventions specific to that population. Air pollution remains a neglected environmental concern in Windhoek, Namibia and people's perceptions about air pollution and health have not been documented. This study investigated the knowledge, attitudes and practices of tertiary students to air pollution in Windhoek.

Methods: Students from five tertiary institutions in Windhoek were included in cross sectional study. A previously validated questionnaire was used to collect data from the study participants. Frequency and a corresponding percentage were reported for categorical data, whereas the association between knowledge of air pollution and perceptions was evaluated using the Chi-square test. Kruskal Wallis rank test was used to assess the statistical difference in knowledge, attitudes and practices. Data analysis was performed using STATA 15 and evaluated at a $5 \%$ level of significance

Results: More than half (59.4\%) of the respondents thought that air pollution was a major problem, while over $90 \%$ knew that air pollution could negatively impact health. The media was found to be the main source of information for respondents (91.1\%). Despite having the knowledge, less than a third (27\%) of the respondents regularly took action out of concern of air pollution. There was a statistically significant association between knowledge, attitudes, and practices to air pollution (all $P<0.05$ ).
\end{abstract}

Conclusions: Air pollution interventions targeting tertiary students should be aimed at informing them on ways in which they could contribute individually and collectively to reducing air pollution and its negative effects.

\section{Keywords:}

Air pollution, Windhoek, Namibia, Tertiary students 


\section{Background}

Air pollution is a global health challenge with its effect observed especially in Asian countries and other developing countries [1,2]. The common health effects associated with air pollution include increased burden of heart and lung disease, respiratory disease, infant and child mortality, skin disease, allergic reaction, cancer, and increased hospital admission [3-5].

The World Health Organization (WHO) estimated that 9 out of 10 people in the world breathe polluted air, and at least seven million people worldwide die annually as a result of exposure to air pollution $[1,6]$. The burden of diseases associated with air pollution has a more severe impact than the combination of smoking, diabetes and road accidents [2, 6-8]. In 2016, 4.2 million people died from outdoor; and 3.8 million from indoor air pollution relatedillness, mainly in low and middle-income countries $[2,7,8]$. Air pollution effects have gone far beyond affecting human health. In recent studies air pollution has been associated with reduction in tourism, and poor school attendance. [9,10].

Some countries such as China have made significant progress in reducing the level of air pollution within their highly affected cities. This was done through targeted regulations as well as educating the community to combat air pollution $[11,12]$. The change in people's knowledge, attitudes, and practices to air pollution has contributed to the improvement of air pollution regulations in some cities in China [12,13].

On the other hand, few sub-Sahara African (SSA) countries have prioritised the prevention and control of air pollution, despite sufficient scientific evidence linking air pollution to adverse health effects [14]. Many cities in Africa are experiencing a deterioration in air quality standards [14]. Although some African countries have regulations in place to control air pollution and institutions for monitoring the air quality, those institutions are not yet efficient enough to yield the reduction in air pollution level as recommended by the WHO $[18,19]$.

The health and environmental implications of air pollution in Africa is not fully understood due to limited data on air pollution [8]. Rapid population growth has increased utilisation of motor vehicles, while rapid industrialisation has been associated with an increase in air pollution levels in SSA. Globally, the largest particulate matter (PM) proportion in air was recorded in SSA [7,14]. In Namibia, air pollution has not been not considered to be a major problem because the population is small, vehicle density is low; and other sources of indoor air pollution in rural villages are considered insignificant, despite the fact that the effects of air pollution were observed to have increased from $10 \%$ to $15 \%[15,16]$. Due to the potentially high level of air pollution in many African cities, the burden of the disease linked to air pollution might be underestimated and this area remains understudied [16].

A study investigating the knowledge, attitude and practices (KAP) of tertiary students in regard to air pollution in Namibia could be used for the development of air pollution interventions in the City of Windhoek $(\mathrm{CoW})$.

\section{Methods}

A quantitative research methodology approach with a descriptive cross-sectional study design was used. A validated questionnaire used was adopted from a study on environmental concerns [20]. The questionnaire tool was adjusted based on the study population and settings, and it was subjected to pre-testing prior to data collection. The respondents for the pilot study were students from two tertiary institutions, and they were excluded from the study sample. A total of twenty (20) questionnaires were distributed during the pilot study. The tool was then refined based on the recommendations and observations from the pre-testing.

The data collection tool consisted of 23 questions that required approximately 10-15 minutes to complete. The questions were divided into three sections. Section A was about respondent's general information (question 1-6), section $B$ was the general environmental concerns (question 7-20), and section $C$ was the perceptions and attitude 
towards air pollution (question 21-23). The questionnaire consisted of questions that assessed knowledge of air pollution, perceptions, and attitude towards air pollution. In order to assess knowledge, questions related to knowledge were identified and for each correctly answered question, a score of 1 was allocated. A score of 5 out of 10 was considered an acceptable level of knowledge of air pollution in Namibia.

Selection of students was based on the following criteria; 18 years old and above who were registered for a full-time diploma or degree at any tertiary institution in Windhoek. Students who met the above criteria were randomly invited to participate in the study and were informed of the date and venue for information sharing. During the recruitment process, a convenient sampling approach was used to select the study participants [21]. All students who turned up to the information sharing session and were willing to take part in the study were given a questionnaire to complete. According to Muindi et al, the prevalence of community perceptions of air pollution and related health risks in Nairobi slums was 20\% [22]. This information was used to estimate the $p$ that was used to calculate the sample size. The $q=1-p=1-0.2=0.8$. The desired margin of error for this study was $5 \%$.

Margin of error $(M E)=1.96 *\left(p^{*} \mathrm{q}\right) / \mathrm{n}$

Therefore $\mathrm{n}=(1.96)^{\wedge} 2(0.2 * 0.8) /(\mathrm{ME})^{\wedge} 2=244,2, \mathrm{n}=245$. Response rate estimated at $80 \%$ or 0.8 . The effective sample size is therefore $245 / 0.8=307$.

The inclusion criterion for selection of institutions was that they had to be accredited by the Namibia Qualification Authority (NQA) to offer an undergraduate diploma or degree courses full-time. At the time of the study, ten (10) tertiary institutions in Windhoek were offering accredited diploma or degree courses on a full-time basis [23]. Institutions were approached for permission to conduct this study with their students, and data collection was only done with students from those institutions which permitted this study. The number of student per institution was determined as follows; sample size divided by the number of institutions which granted permission to participate in the study.

Data was initially captured in Epi Data Entry by the assistant researcher, and then double entry verification was done by the researcher. Data verification step was taken if there was any information mismatch when comparing it with the responses from the original questionnaire. The data in the double-entry file was used as final, which was then exported to Microsoft Excel, and Stata version 15. Frequency and a corresponding percentage were reported for categorical data, whereas the association between knowledge of air pollution and perceptions was evaluated using the Chi-square test. Kruskal Wallis rank test was used to assess the statistical difference in knowledge, attitudes and practices. Data analysis was performed using STATA 15 and evaluated at a 5\% level of significance.

\section{Results}

Demographic characteristics of the study participants 
The study collected data from a total of 321 respondents, a $100 \%$ response rate was obtained from respondents from five different tertiary institutions. A total of $176(54.8 \%)$ of the sample were female, $234(72.9 \%)$ were between the age of 18-23 years old, and a total of $10(3.1 \%)$ were over the age of 34 years old. The majority $(128,39.9 \%)$ were in their first year of study, with a total of $69(21.6 \%)$ respondents enrolled in the health field (Table 1).

Table 1: Demographic characteristics of the study participants ( $N=321)$

\begin{tabular}{lll}
\hline Variable and Groups & Frequency & Percentage (\%) \\
Sex & & \\
Male & 145 & 45.17 \\
Female & 176 & 54.83 \\
Age & & \\
$18-23$ & 234 & 72.90 \\
$24-28$ & 56 & 17.45 \\
$29-33$ & 21 & 6.54 \\
$>=34$ & 10 & 3.12 \\
Year of study & & \\
$1^{\text {st }}$ year & 128 & 39.88 \\
$2^{\text {nd }}$ year & 116 & 36.14 \\
$3^{\text {rd }}$ year & 62 & 19.31 \\
$4^{\text {th }}$ year & 15 & 4.67 \\
Field of study & & \\
Science & 44 & 13.75 \\
Health & 69 & 21.56 \\
Economics & 32 & 10.00 \\
Education & 43 & 13.44 \\
Information Technology & 42 & 13.13 \\
Business & 38 & 11.88 \\
Engineering & 6 & 1.88 \\
Art & 46 & 1.38 \\
\hline
\end{tabular}

Table 1. Sample structure $(n=321)$

The general level of Knowledge

Air pollution $(208,69 \%)$, litter $(139,43 \%)$, and traffic $(108,34 \%)$ have been cited as the top three most environmental concern in Windhoek (Figure 1). 


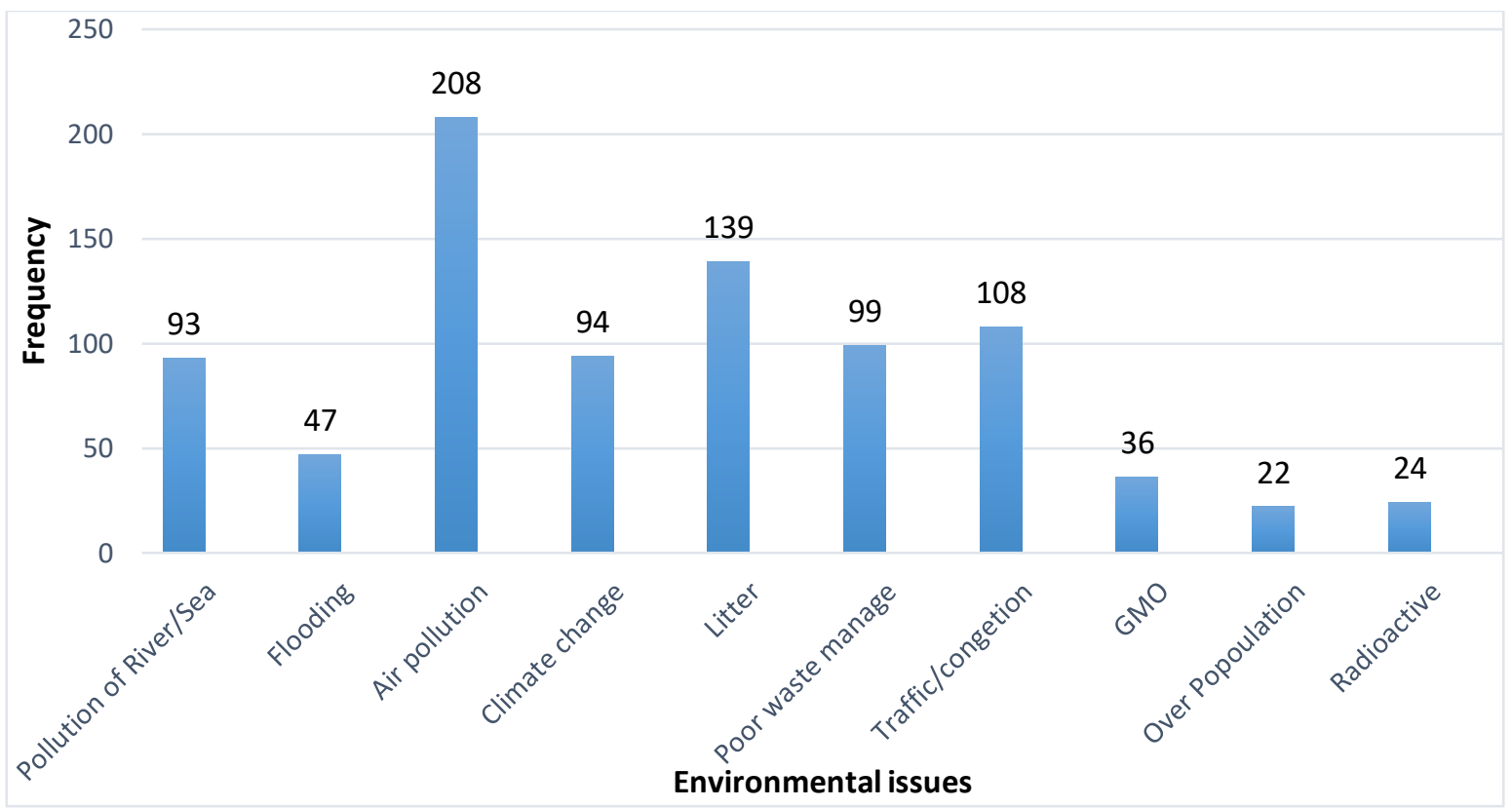

Figure 1. Common environmental concern among tertiary students in Windhoek

Table 2 presents the measure of association between demographic characteristics and knowledge of air pollution. Over $80 \%$ of participants had knowledge of air pollution. There was no statistically significant of an association between gender, year of study and stream of the study with knowledge of air pollution $(p>0.05)$.

Table 2. Knowledge of air pollution by demographic factors

\begin{tabular}{llcc}
\hline & \multicolumn{2}{c}{ Knowledge [n (\%)] } & \\
Demographic & Yes [274 (85.4\%)] & No [47 (14.6\%)] & *P-Value \\
\hline Male & $118(43.1)$ & $27(57.5)$ & 0.07 \\
Female & $156(56.9)$ & $20(42.5)$ & \\
Year of Study & & & \\
First & $105(38.2)$ & $23(48.9)$ & 0.15 \\
Second & $103(37.6)$ & $13(27.7)$ & \\
Third & $51(18.6)$ & $11(23.4)$ & \\
Fourth & $15(5.5)$ & 0 & \\
Stream of study & & $9(19.2)$ & \\
Science & $35(12.8)$ & $7(14.9)$ & \\
Health & $62(22.7)$ & $6(12.8)$ & \\
Economics & $26(9.5)$ & $4(8.5)$ \\
Education & $39(14.3)$ & $6(12.8)$ \\
IT & $36(13.2)$ & $7(14.9)$ & \\
Business & $31(11.4)$ & $2(4.3)$ & \\
Engineering & $4(1.5)$ & $6(12.8)$ & \\
Other & $40(14.7)$ &
\end{tabular}

*Note: P-value of the $\chi^{2}$ test of association 
Table 3 below presents the relationship between knowledge and perceived health-related issues among participants. About $60 \%$ of participants who are aware of air pollution believe that it is a major problem in the CoW. Of the 274 participants who had knowledge of pollution, $162(59.1 \%)$ indicated that their health had been affected by air pollution in the past. From a total of 274 knowledgeable participants, $83.8 \%$ perceived that air pollution affected their visibility, $91.1 \%$ their outdoor activities, $91.6 \%$ make them do more to stay healthy and $93.1 \%$ perceived that air pollution has led them into depression, while less than $50 \%$ think breathing and eye irritation are less affected by air pollution. There was no statistically significant of an association between perceived health problems with the knowledge of air pollution $(\mathrm{p}>0.05)$.

Table 3: Knowledge of air pollution and perceived health-related problems

\begin{tabular}{|c|c|c|c|}
\hline Perception & $\begin{array}{l}\text { Knowledge } \\
\text { Yes [274 }(85.4 \%)]\end{array}$ & $\begin{array}{c}{[n(\%)]} \\
\text { No }[47(14.6 \%)]\end{array}$ & *P-Value \\
\hline \multicolumn{4}{|l|}{ Major Problem } \\
\hline Yes & $167(61.2)$ & $23(48.9)$ & \\
\hline No & $85(31.1)$ & $20(42.6)$ & 0.27 \\
\hline Don't Know & $21(7.7)$ & $4(8.5)$ & \\
\hline \multicolumn{4}{|c|}{ Ever been affected by air pollution } \\
\hline Yes & $162(59.1)$ & $29(61.2)$ & \\
\hline No & $89(32.5)$ & $15(31.9)$ & 0.88 \\
\hline Don't Know & $23(8.4)$ & $3(6.38)$ & \\
\hline \multicolumn{4}{|l|}{ Health Factors } \\
\hline \multicolumn{4}{|l|}{ Visibility } \\
\hline Yes & $171(83.8)$ & $22(75.9)$ & 0.29 \\
\hline No & $33(16.2)$ & $7(24.1)$ & \\
\hline \multicolumn{4}{|l|}{ Breathing } \\
\hline Yes & $90(44.1)$ & $15(51.7)$ & 0.44 \\
\hline No & 114 (55.9) & $14(48.3)$ & \\
\hline \multicolumn{4}{|c|}{ Outdoor activities } \\
\hline Yes & $185(91.1)$ & $15(51.7)$ & 0.18 \\
\hline No & $18(8.9)$ & $14(48.3)$ & \\
\hline \multicolumn{4}{|c|}{ Doing more to stay healthy } \\
\hline Yes & $186(91.6)$ & $29(100)$ & 0.14 \\
\hline No & $17(8.4)$ & 0 & \\
\hline \multicolumn{4}{|l|}{ Depression } \\
\hline Yes & $190(93.1)$ & $25(86.2)$ & 0.25 \\
\hline No & $14(6.9)$ & $4(13.8)$ & \\
\hline \multicolumn{4}{|l|}{ Irritation } \\
\hline Yes & $92(45.1)$ & $16(55.2)$ & 0.31 \\
\hline No & $112(54.9)$ & $13(44.8)$ & \\
\hline
\end{tabular}

*Note: P-value of the $\chi^{2}$ test of association

Table 4 presents the measure of statistically significant difference between mean knowledge score, attitude, and behaviour toward air pollution. There was a statistically significant difference between mean knowledge, attitude and behaviour $(\mathrm{p}<0.05)$ except for taking actions out of concern of air pollution $(\mathrm{p}>0.09)$. 
Table 4: Mean knowledge score by behavior and attitude among tertiary students $(\mathrm{N}=321)$

Mean knowledge

Behaviour and Attitude

Have you ever taken action out of concern of air pollution

yes

no

\section{Don't Know}

We can all do our part to reduce air pollution

Agree

Neutral

Disagree

There is no point taking action because no one else is doing it
Agree
Neutral
Disagree
Will take action if I knew how to prevent air pollution

4.34

3.89

5.11

Agree

Neutral

4.14

Disagree

3.6

4.42

3.83

5.02

95\% CI

$4.56 ; 5.16$

I don't believe pollution is a problem

Agree

Neutral

Disagree

*Note: P-value of Kruskal Wallis rank test
$3.81 ; 5.02$

$2.93 ; 4.73$

$<0.01$
$3.92 ; 4.76$

4.74; 5.08

$3.32 ; 4.90$

$4.82 ; 5.11$

$3.42 ; 4.74$

0.04

$3.81 ; 5.75$

$3.34 ; 4.42$

$<0.01$

4.97. 5.26

4.90; 5.17

$3.40 ; 4.87$

$<0.01$

$2.81 ; 4.39$ $4.88 ; 5.16$

\subsection{Perceptions and attitudes toward air pollution}

Respondent's perception and attitude towards air pollution were also analysed in this study. Respondents were asked to what extent they believe that air pollution is inevitable due to the modern way of living? A total of 225 (73.3\%) thought air pollution is inevitable (85 Strongly agree, 140 Agree), and more than 80\% acknowledged air pollution as a real problem. Although they said, air pollution is inevitable, participants have positive attitudes toward its control as the majority $(65.1 \%$, and $28.3 \%$ ) think that reduction in the effects of air pollution is a collective responsibility (Figure 2). About $80 \%$ of respondents admitted that they would take action if they knew better ways of reducing air pollution. On controlling air pollution, a total of 189 (60.6\%) participants agreed that there is a need to penalise all polluting companies, as well as put a strict regulation to monitor car emissions more frequently to ensure that pollution from motor vehicles is minimised. 
Figure 2. Reducing the effects of air pollution is a collective responsibility

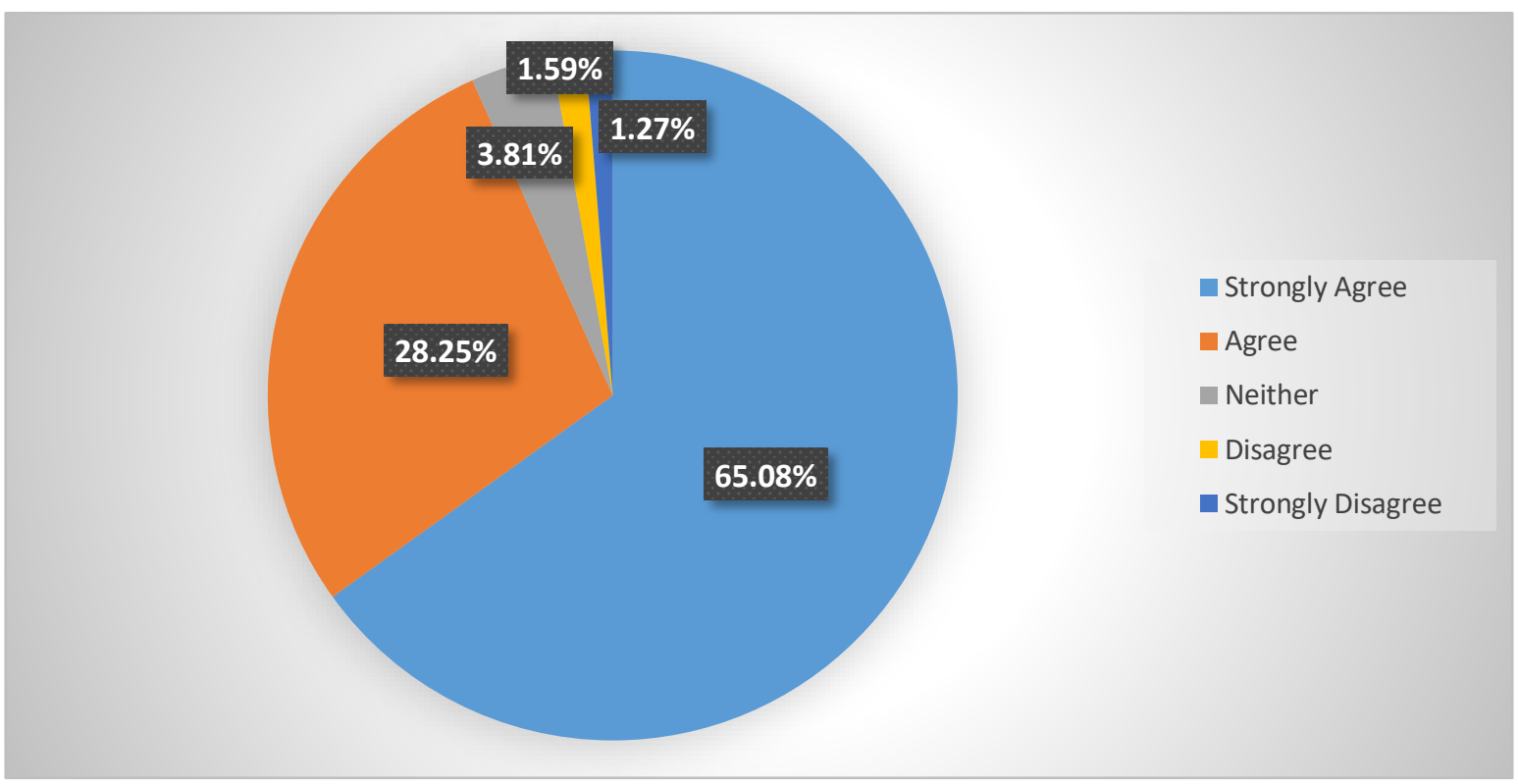

Participants identified that the most reliable source of air pollution information is from the researchers/scientists (237, $76.9 \%)$, the government $(140,45.5 \%)$, media $(165,53.7 \%)$, family or friends $(113,36.5 \%)$, Tertiary institutions (142, $47.2 \%)$, and environmental organizations $(200,65.2 \%)$.

\section{Discussion}

The aim of this study was to investigate the knowledge, attitude, and practices of students regarding air pollution in order to suggest air pollution interventions in the CoW. Air pollution, littering and traffic/congestion was identified as the most common environmental concern in the CoW. This is similar to the global and national call for air pollution and climate change to be considered among the priority list of common environmental problems that need to be addressed as a matter of urgency $[8,16,24]$. However, according to the official information from the Government Republic of Namibia (GRN), air pollution is considered not among the most pressing environmental problem in Namibia [15].

Participants perceived air pollution as a major problem and that it had affected them or their family negatively. Their attitude towards air pollution prevention is positive as the majority indicated that they would be willing to contribute to air pollution control measures and also urged the government to take an active role in promoting a healthy environment. There was no statistically significant association between knowledge of air pollution and age, year of study or stream.

Regarding air pollution knowledge, respondents had some basic information and understanding of air pollution. The majority understood that there was an association between air pollution and health problems, with about $60 \%$ perceiving that air pollution had affected them in different ways such as having difficulty in breathing, irritation of the eyes; and poor visibility. The effects of air pollution on humans can be short or long term. The short term effects of air pollution can include an allergic reaction, irritation of the eyes and skin; and difficulty in breathing. Whereas the long term effects can be chronic diseases such as asthma, heart diseases, lung cancer, and non-communicable diseases [25-27]. 
Information from research institutions, organisations and media was the most common way of passing on information and interventions pertaining to air pollution and health. Among respondents who were knowledgeable about an association between air pollution and health problems, few regularly took action out of concern to reduce air pollution. This study did not obtain further investigate factors leading to lack of air pollution prevention activities among respondents. However, it has been observed globally that lack of information may lead to poor action $[28,29]$. This study found that there was a statistical significant association between the knowledge, behaviour, and attitudes regarding air pollution (P-values $>0.05$ ). Increased air pollution awareness among community members can lead to early acceptance of air pollution policies, and interventions as well as a willingness to take protective measures [30,31].

Although the majority of respondents thought that motor vehicles or bikes were the main cause of air pollution in the CoW, most indicated that they would like to buy a car once they started working. This might have a future implication on the density of motor vehicles within the city, as the increased use of motor vehicles is linked to ambient air pollution [17,32]. A study conducted in South Korea found that carbon monoxide (CO) emissions came from vehicles (35\%) and industrial sites (30\%), while PM10 was associated with the local automotive industry [32].

There was general agreement among respondents that the fight against air pollution should be a collective effort as they indicated that individuals, the $\mathrm{CoW}$, and government have the overall responsibility in tackling air pollution. A modern lifestyle characterised by globalisation and industrialisation has led to an increased level of air pollution [7,32]. Respondent's general knowledge of air pollution was good and that they had a positive attitude toward its control. Willingness to participate in air pollution interventions was shown by almost all respondedts $(>90)$, who were willing to take action which could lead to a reduction in air pollution effects. The roles of an individual in the fight against air pollution were found to be crucial in China [31].

The study also investigated factors that could reduce air pollution in the CoW. The majority of the respondents suggested that all polluting companies should be penalised for polluting the environment. More than $90 \%$ agreed that car emissions should be checked and controlled more frequently as a measure to reduce air pollution in the city. Over $90 \%$ believed that the government needed to do more to promote and encourage a better environment.

The fight for a better environment should, however not be limited to the government alone. Respondents believes that there was a need to involve all stakeholders such as family and friends, the media, environmental organisations, tertiary institutions and researchers. This is in line with other studies, which have emphasised the need for a collective effort in improving the air quality in the city [30].

\section{Limitations}

The lack of discussion and regulation on air pollution in the CoW may have a negative effect on resident's knowledge and practices in regard to air pollution. The result of this study is therefore based on perceptions from respondents. The data collection tool was adopted from a survey study, the questions were adjusted to fit the study settings, and this could affect or change the theoretical guide used when designing each question, however this have no effects towards the outcome of the study, the tool was piloted and peer reviewed. Due to time constraint to complete this study as well as availability of resources, this study opted to use tertiary students. The results of this study therefore cannot be generalized to the entire CoW.

\section{Conclusions}

Understanding people's knowledge of air pollution may help guide responses or communication of information related to air pollution. This paper represents the first study done in Windhoek looking at tertiary students' knowledge, attitude and responses regarding air pollution. There is a need to raise awareness on air pollution among tertiary students, which is aimed at informing them on ways in which they can contribute individually and collectively towards reducing the effects of air pollution. The use of media would be the most effective way of passing information regarding air 
pollution preventive measures. The government can no longer ignore air pollution on the basis of the small population and low car density, but rather put measures in place which are aimed at controlling air pollution. There is a need for further study to determine the level of air pollution in the city as well as the common pollutants in the city in order to inform specific interventions.

\section{Declarations}

Ethics approval and consent to participate: This study received ethical approval from the Research Ethics Committee, Faculty of Health Sciences, University of Pretoria (approval number 141 2018), and was subjected to further ethical clearance from each tertiary institution that participated in this study. An informed consent was obtained from all study participants.

Consent for publication: Not applicable

Availability of data and materials: The datasets used and/or analysed during the current study are available from the corresponding author on reasonable request.

Competing interests: The authors declare that they have no competing interests.

Funding: This research received no external funding.

Author's Contributions: H.K and V.N, participated in the conceptualisation and design of the study, data collection, statistical analysis, and interpretation of the results drafted and critically revised the manuscript. T.N participated in the statistical analysis and interpretation of the results, drafted and critically revised the manuscript. All authors have read and approved the final manuscript.

Acknowledgements: The researcher would like to acknowledge Professor Cheryl Mccrindle offering proof reading and English editing of this manuscript.

\section{References}

1. World Health Organization. Ambient air pollution: A global assessment of exposure and burden of disease. Available online: https://www.who.int/phe/publications/air-pollution-global-assessment/en/ (accessed on 24 February 2019).

2. World Health Organization: Regional Office for Europe. Review of evidence on health aspects of air pollutionREVIHAAP Project, Technical report. Available online: http://www.euro.who.int/_data/assets/pdf_file/0004/193108/REVIHAAP-Final-technical-report.pdf (accessed on 04 March 2019).

3. Tian, Y.; Liu, H.; Liang, T.; Xiang, X.; Li, M.; Juan, J.l; Song, J.; Cao, Y.; Wang, X.; Chen, L.; Wei, C.; Gao, P.; Hu, Y. Ambient Air Pollution and Daily Hospital Admissions: A Nationwide Study in 218 Chinese Cities. Environ Pollut. 2018, 242, 1042-1049, doi: 10.1016/j.envpol.2018.07.116.

4. Huang; Fangfang; Luo; Yanxia; Tan; Peng; Xu; Qin; Tao; Lixin; et al. Gaseous air pollution and the risk for stroke admissions: A case-crossover study in Beijing, China. Int J Environ Res Public Health. 2017,14, 1-14.

5. Knibbs, L. D.; Cortés de Waterman Adriana, M.; Toelle, B. G.; Guo, Y.; Denison, L.; Jalaludin, B.; Marks, G. B.; Williams, G. M. The Australian Child Health and Air Pollution Study (ACHAPS): A National Population-Based Cross-Sectional Study of Long-Term Exposure to Outdoor Air Pollution, Asthma, and Lung Function. Environ. Int. 2018, 120, 394-403. doi: 10.1016/j.envint.2018.08.025.

6. World Health Organization. Air pollution. Available online: https://www.who.int/news-room/air-pollution (accessed on 17 March 2019).

7. Health Effects Institute. State of Global Air 2018: A SPECIAL REPORT ON GLOBAL EXPOSURE TO AIR POLLUTION AND ITS DISEASE BURDEN. Available online: https://www.stateofglobalair.org/sites/default/files/soga-2018-report.pdf (accessed on 5 March 2019).

8. World Health Organization. Country estimates on air pollution exposure and health impact. Available online: https://www.who.int/en/news-room/detail/27-09-2016-who-releases-country-estimates-on-air-pollutionexposure-and-health-impact (access on 20 March 2019).

9. Sajjad, F.; Noreen, U.; Zaman, K. Climate change and air pollution jointly creating a nightmare for the tourism industry. Environ Sci Pollut Res. 2014, 21,1-17. 
10. Chen, S.; Guo, C.; Huang, X. Air Pollution, Student Health, and School Absences: Evidence from China. J. Environ. Econ. Manag. 2018, 92, 465-497. doi: 10.1016/j.jeem.2018.10.002.

11. Zheng, S.; Yi, H.; Li, H. The impacts of provincial energy and environmental policies on air pollution control in China. Renew Sust Energ Rev. 2015, 49, 386-394, doi:10.1016/j. rser.2015.04.088.

12. Xujun Q.; Guozhang X.; Li L.; Yueping S.; Tianfeng H.; Yajun L.; Zuyao Y.; Wan Wei Z.; Jiaying X. Knowledge and perceptions of air pollution in Ningbo, China. BMC Public Health. 2016, 16, 1-7.

13. Lyu, X.P.; Zeng, L.W.; Guo, H.; Simpson, I.J.; Ling, Z.H.; Wang, Y.; Murray, C.; Louie, P.K.K.; Lam, S.H.M.; Blake, D.R. Evaluation of the effectiveness of air pollution control measures in Hong Kong. Environ Pollut. 2017, 220, 87-94.

14. Amegah, A.; Agyei-Mensah, S. Urban air pollution in sub-Saharan Africa: Time for action. Environ Pollut. 2017, 220,738-743, doi:10.1016/j. envpol.2016.09.042.

15. World Health Organization: Office for African Region. Namibia: Analytical summary - The physical environment. Available online: http://www.aho.afro.who.int/profiles_information/index.php/Namibia:Analytical_summary__The_physical_environment (accessed on 2 September 2017).

16. Hamatui, N.; Beynon, C. Particulate matter and respiratory symptoms among adults living in Windhoek, Namibia: A cross-sectional descriptive study. Int J Environ Res Public Health. 2017,14,1-15.

17. Petkova, E.P.; Jack, D.W.; Volavka-Close, N.H.; Kinney, P.L. Particulate Matter pollution in African cities. Int J Air Qual Atmos Health. 2013, 6,1-13.

18. Bethan, T.J.; Hanspeter, T. Combating air pollution in Botswana. Available online: https://www.environmentalistonline.com/article/combating-air-pollution-botswana (accessed on 2 September 2017).

19. Mdluli, T.N. 2015 State of air report and National air quality indicator. The 10th Air Quality Governance Lekgotla, Bloemfontein, South Africa, 28-29 September 2015. Available online: http://www.airqualitylekgotla.co.za/assets/session-1.2-2015-09-27state-of-air-presentation_and-naqi.pdf (accessed on 2 September 2017).

20. The University of Bath. Survey Questionnaire: Climate change version. Available online: https://www.researchgate.net/file.PostFileLoader.html?id=581d5c10615e2724796f3151\&assetKey=AS\%3A42 $4915343024128 \% 401478319120254$ (accessed on 2 September 2017).

21. Ehrlich R, Joubert G, editors. Epidemiology: A Research Manual for South Africa. 3rd ed. Cape Town: Oxford University Press Southern Africa; 2014.

22. Muindi K, Egondi T, Kimani-Murage E, Rocklov J, Nawi Ng. "We are used to this": A qualitative assessment of the perceptions of and attitudes towards air pollution amongst slum residents in Nairobi. BMC Public Health. 2014, 14:226 http://www.biomedcentral.com/1471-2458/14/226.

23. Namibia Qualifications Authority. Namibian Accredited Institutions. Available online: http://www.namqa.org (accessed on 04 March 2018).

24. United Nations Environment. Air pollution and climate change: Two sides of the same coin. Available online: https://www.unenvironment.org/news-and-stories/story/air-pollution-and-climate-change-two-sides-same-coin (accessed on 28 April 2019).

25. Xiao, S.; Liu, R.; Wei, Y.; Feng, L.; Lv, X.; Tang, F. (2016). Air pollution and blood lipid markers levels: Estimating short and long-term effects on elderly hypertension inpatients complicated with or without type 2 diabetes. Environ Pollut. 2016, 215, 135-140, doi:10.1016/j. envpol.2016.05.007.

26. Kim K.E.; Cho, D.; Park, H.J. Air pollution and skin diseases: Adverse effects of airborne particulate matter on various skin diseases. Life Sci. 2016, 152, 126-134.

27. Coker, E.; Kizito, S. (2018). A narrative review of the human health effects of ambient air pollution in sub-Saharan Africa: An urgent need for health effects studies. Int J Environ Res Public Health. 2018, 15, 1-15, doi:10.3390/ijerph15030427.

28. Kulözü, N. Youths' perception and knowledge towards environmental problems in a developing country: In the case of Atatürk University, Turkey. Environ Sci Pollut Res Int. 2016, 23, 1-10, https://doi.org/10.1007/s11356016-6693-2. 
29. Liao, X.; Tu, H.; Maddock, J.E.; Fan, S.; Lan, G.; Wu, Y.; Yuan, Z.; Lu, Y. Residents' perception of air quality, pollution sources, and air pollution control in Nanchang, China. Atmos Pollut Res. 2015, 6, 835-841, doi:10.5094/APR.2015.092.

30. Liu, R.; Liu, X.; Pan, B.; Zhu, H.; Yuan, Z.; Lu, Y. Willingness to pay for improved air quality and influencing factors among manufacturing workers in Nanchang, China. Sustainability, 2018,10, 1613-1613, doi:10.3390/su1005161

31. De Pretto, L.; Acreman, S.; Ashfold, M.J.; Mohankumar, S.K.; Campos-Arceiz, A. The Link between Knowledge, Attitudes and Practices in Relation to Atmospheric Haze Pollution in Peninsular Malaysia. PLoS ONE. 2015, 10,1-18. doi:10.1371/journal.pone.0143655

32. Hasunuma, H.; Ishimaru, Y.; Yoda, Y.; Shima, M. Decline of ambient air pollution levels due to measures to control automobile emissions and effects on the prevalence of respiratory and allergic disorders among children in Japan. Environ. Res. 2014, 131, 111-118. doi:10.1016/j. envres.2014.03.007.

Additional file 1: Data collection tool. Self-administered questionnaire that was used to collect data from study participants. 
Figures

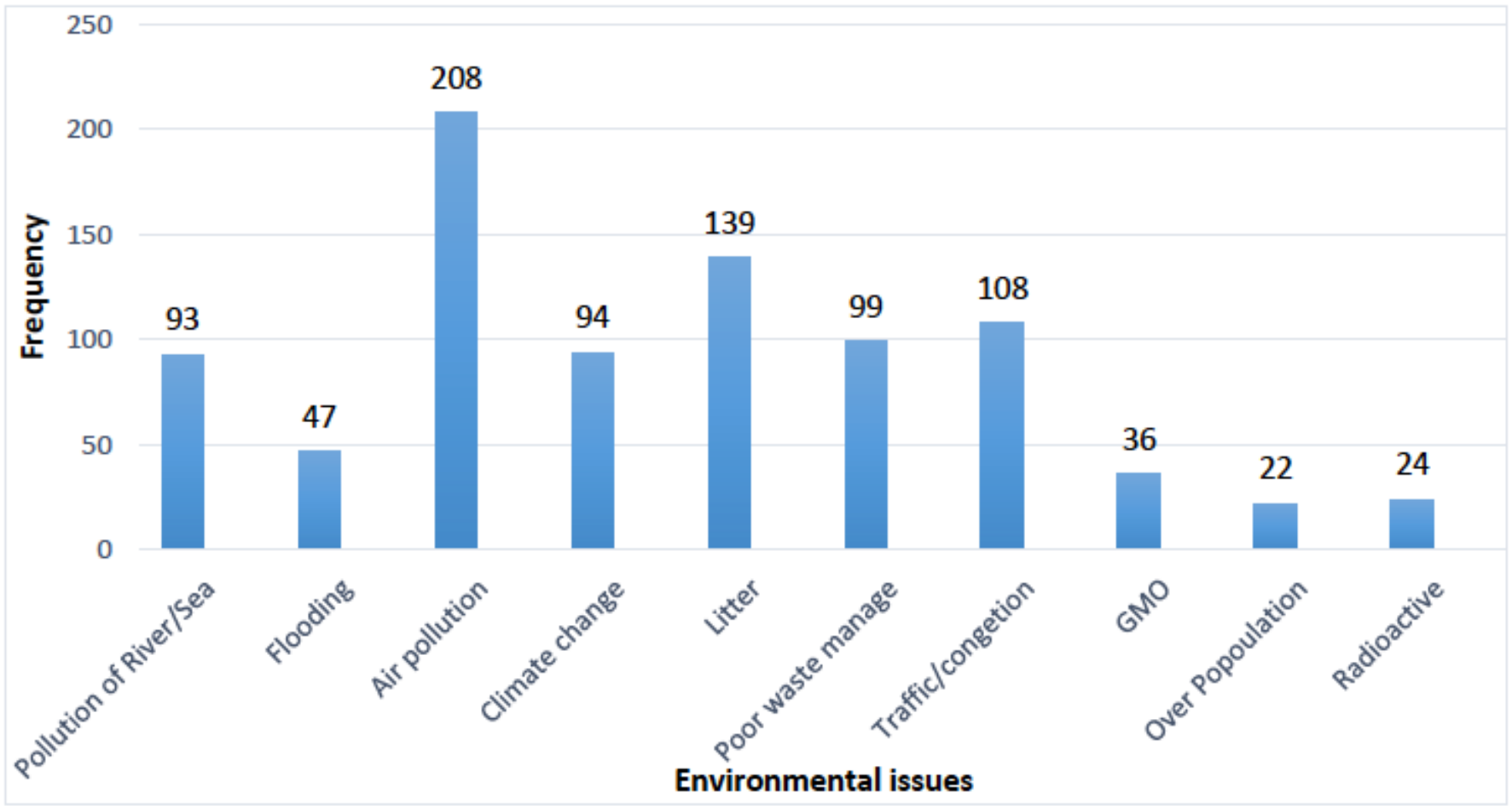

Figure 1

Common environmental concern among tertiary students in Windhoek

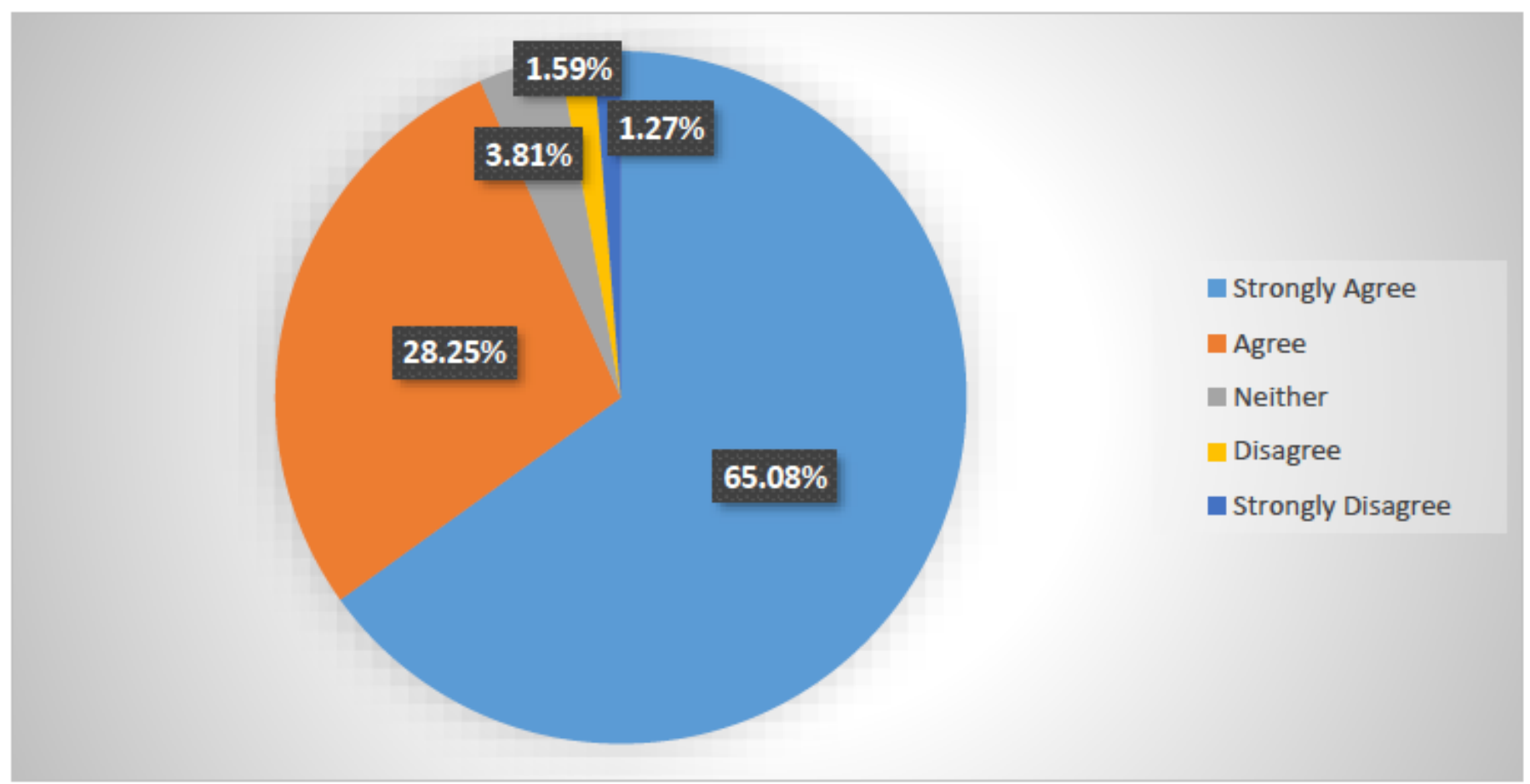


Figure 2

Reducing the effects of air pollution is a collective responsibility

\section{Supplementary Files}

This is a list of supplementary files associated with this preprint. Click to download.

- DATACOLLECTIONTOOL.pdf

- Tables.pdf 